\title{
Fatigue and fracture resistance of ferritic ductile cast iron: the effect of $\mathrm{Sb}$ and solidification time
}

\author{
Matteo Benedetti ${ }^{1,}$, Vigilio Fontanari ${ }^{1}$, and Danilo Lusuardi ${ }^{2}$ \\ ${ }^{1}$ Department of Industrial Engineering, University of Trento, 38123 Trento, Italy \\ ${ }^{2}$ Fonderie Ariotti S.p.A., 25030 Adro BS, Italy
}

\begin{abstract}
In this paper, we explore the effect of inoculants and solidification time on the mechanical properties of an EN-GJS-400-type ferritic ductile cast iron (DCI). For this purpose, static tensile, rotating bending fatigue, fatigue crack growth and fracture toughness tests are carried out on three different material conditions. They are produced under fast cooling (solidification time $2 \mathrm{~h} 45 \mathrm{~min}$ ), representative of thin walled castings, and very slow cooling (solidification time $10-13 \mathrm{~h}$ ), representative of thick walled castings, this latter with and without the addition of Sb. It has been found that the long solidification time leads to an overgrowth and degeneration of the spheroidal graphite nodules. The addition of Sb avoids the formation of chunky graphite observed in the slowly cooled condition but results in large exploded graphite nodules. These effects impact negatively on tensile strength, total elongation and fatigue strength. Conversely, the resistance to fatigue crack growth is even superior and the fracture toughness comparable to that of the fast cooled condition. Metallurgical and fractographic analyses are carried out to explain this behaviour.
\end{abstract}

\section{Introduction}

Low production cost and excellent castability make ductile cast iron (DCI) the preferred material choice when low-to-moderately stressed mechanical components of complicated shape and large dimensions must be manufactured. The microstructural control of DCI is of paramount importance as it greatly influences a wide range of mechanical properties. The typical microstructure consists of graphite nodules dispersed in a matrix that can be ferritic, ferritic and/or pearlitic depending on the alloy formulation, the casting control and the final heat treatment. The ferritic matrix displays usually the lower tensile and fatigue strength but also a noticeable ductility, which have promoted the DCI in the production of thick walled parts undergoing in service low/medium levels of mechanical stresses.

Casting large volume parts of weight on the order of tens of tons is particularly critical as the control of the final microstructure is rather difficult [1-3]. In fact the resulting long solidification time introduces into the material intrinsic defects, such as solidification cavities or poor graphite nodularity, dross and degenerated (chunky and spiky) graphite, which can be tolerated up to a certain level. It was found that the increase in nonnodular graphite content decreases the mechanical strength; indeed, the ultimate tensile strength and mostly the elongation to fracture are severely lowered, despite hardness and yield strength remain nearly unaffected. In particular, the increase of chunky content up to $20 \%$ and more induces a significant decrease in fatigue lifetime, with a drop of fatigue limit on the order of $15 \%-20 \%$ [4]. Sometimes, small amounts of rare earth elements such as $\mathrm{Ce}, \mathrm{Nd}, \mathrm{Pr}, \mathrm{Sm}$ and $\mathrm{Gd}$ are inoculated into the casting to induce graphite spheroidization but at the cost of the formation of chunky graphite [5-7].

While the effect of chunky graphite on static and cyclic properties has been largely investigated in the literature, its effect on fatigue crack growth rate and fracture toughness is not yet clear. This is however of paramount importance when designing high-added value components of large dimensions, such as those employed in MW-series wind turbines, which cannot rely on the knowledge of the fatigue strength only. In fact, infinite life design approaches usually take large safety margins thus resulting in very heavy constructions, while safe life approaches suffer from large uncertainty on the actual lifetime of the component prior to its withdrawal from service. Damage tolerant design and structural health monitoring approaches have been proposed to overcome these limitations. According to these approaches, the fatigue life is exclusively thought of as the propagation of cracks up to a critical size leading to structural collapse or functionality loss. Therefore, they require a detailed characterization of fracture toughness and fatigue crack growth resistance of the castings, in order to assess the critical crack size and the time to propagation to this critical value. In the present paper, we address this latter issue by investigating the crack growth resistance of a DCI under three different microstructural conditions. They are produced under fast, representative of thin walled castings, and very slow

Corresponding author: matteo.benedetti@unitn.it 
cooling, representative of thick walled castings, this latter with and without the addition of inoculants able to promote graphite spheroidization. Static tensile, fatigue and fracture mechanics tests are performed to quantify the resistance to fatigue crack initiation and propagation as well as the fracture toughness. The discussion is complemented with metallurgical and fractographic analyses.

\section{Material and Experimental Procedures}

The experimentation is performed on an EN-GJS-400type ferritic DCI. The condition representative of thinwalled castings, hereinafter denoted as "fast cooling" (FC), is obtained from the solidification of a cylinder with $300 \mathrm{~mm}$ diameter and $520 \mathrm{~mm}$ height exposed to natural air convection (solidification time of $2 \mathrm{~h} 45 \mathrm{~min}$ ). Long solidification times representative of thin-walled castings are obtained from an innovative production line described in [8]. It consists of an electric furnace where the solidification of a cylinder with $240 \mathrm{~mm}$ diameter and $260 \mathrm{~mm}$ height (about $80 \mathrm{~kg}$ mass) takes place under controlled cooling conditions to achieve solidification time of $10-13 \mathrm{~h}$. In this way, two material variants are obtained, without and with the addition of $\mathrm{Sb}$ and denoted as "slow-cooling" (SC) and "slow-cooling+Sb" $(\mathrm{SC}+\mathrm{Sb})$, respectively. Specifically, $50 \mathrm{ppm}$ of $\mathrm{Sb}$ are introduced into the casting to suppress the formation of chunky graphite observed in the SC condition.

Monotonic tensile tests are performed according to the standard UNI EN ISO 6892-1 on dog-bone coupons (14 mm gauge diameter, $84 \mathrm{~mm}$ parallel length), using a servo-hydraulic universal testing machine, equipped with hydraulic grips, a load cell of $200 \mathrm{kN}$. The yield strength is determined as the $0.2 \%$ offset yield stress.

Fatigue tests are performed on hourglass specimens according to the standard ASTM E466. Rotating bending fatigue tests (load ratio $\mathrm{R}=-1$ ) are carried out under load-control at a nominal frequency of $100 \mathrm{~Hz}$ in laboratory environment $\left(25^{\circ} \mathrm{C}, 60 \%\right.$ R.H. $)$. The fatigue strength corresponding to a fatigue life of $5 \times 10^{6}$ cycles is obtained by a staircase procedure, employing 15 samples and $10 \mathrm{MPa}$ stress increments.

The fracture mechanics tests are carried out on compact $\mathrm{C}(\mathrm{T})$ specimens whose geometry, compliant with the standard ASTM E1820-09, is illustrated in Figure 1. Specifically, $K_{I c}$ fracture toughness and fatigue crack growth rate tests are performed on 32 and $10 \mathrm{~mm}$ thick specimens, respectively. The initial notch of all $\mathrm{C}(\mathrm{T})$ specimens is Electro Discharge Machined (EDM) with a wire of $0.5 \mathrm{~mm}$ diameter to facilitate the followup pre-cracking process.

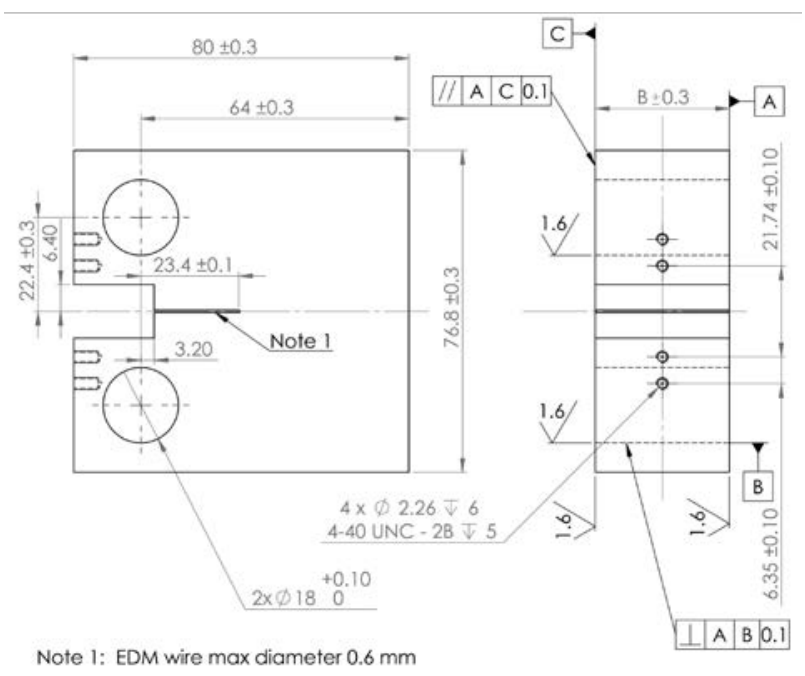

Fig. 1. Compact tension $\mathrm{C}(\mathrm{T})$ specimens used in fracture mechanics tests. Dimensions are given in $\mathrm{mm}$. The thickness B of the $C(T)$ specimens is equal to $10 \mathrm{~mm}$ and to $32 \mathrm{~mm}$ for fatigue crack growth rate and fracture toughness tests, respectively.

The fatigue crack growth rate testing is performed according to the standard ASTM E647-08. The experiments are conducted in the laboratory environment on a resonant testing machine Rumul Testronic $50 \mathrm{kN}$. A sinusoidal pulsating load waveform is applied at a frequency of $\sim 100 \mathrm{~Hz}$. Tests are performed at three load ratios $\mathrm{R}$, namely $0.1,0.5$ and 0.75 . A Fractomat ${ }^{\circledR}$ apparatus based on the indirect potential drop method is used to continuously measure the crack length. Periodically, the crack length on the back face of the sample is inspected using a travelling microscope to make sure that the two crack lengths do not differ by more than 0.25 times the sample thickness, as prescribed by the standard ASTM E647-08. The crack growth rates are calculated from discrete crack length increments of $0.3 \mathrm{~mm}$, necessary for sampling the fatigue crack growth resistance of the fairly coarse material microstructure. The tests are performed in two distinct phases. In the initial force-shedding phase, the applied $\Delta K$ is exponentially reduced by setting the decay constant $\mathrm{C}=0.08 \mathrm{~mm}^{-1}$ until reaching near-threshold fatigue crack growth conditions. A specific testing campaign was carried out in [9] to determine the minimum crack length sufficient for the material to fully deploy extrinsic crack growth resistance mechanisms. Only after reaching this crack size, the final part of the experiments is performed under constant force amplitude and the crack growth rate data are used to build the $\mathrm{d} a / \mathrm{d} N$ vs $\Delta K$ curves. After the fatigue tests, the specimens are sectioned across the thickness and metallographic samples are extracted in order to investigate the crack front profile. Fracture surfaces are investigated using a JEOL JSM-IT300LV SEM.

Specimens for fracture toughness tests are fatigue precracked to a crack-length-to-specimen-width of about 0.5 using the same resonant testing machine in laboratory environment under K-controlled conditions (load ratio $\mathrm{R}=0.1$ ) suitable to maintain the crack growth rate below $10^{-8} \mathrm{~m} /$ cycle. After precracking, to enforce 
the plane strain condition, 20\% V-notch side grooves are machined on the samples, resulting in a net thickness $(\mathrm{BN})$ of $25.6 \mathrm{~mm}$. Subsequently, the samples are monotonically loaded up to fracture to determine the $\mathrm{Kc}$ fracture toughness $\left(\mathrm{d} K / \mathrm{d} t=1 \mathrm{MPa} V \mathrm{~m} \cdot \mathrm{s}^{-1}\right.$, room temperature air) using a $100 \mathrm{kN}$ servo-hydraulic testing machine equipped with a clip-gauge mounted on knife edges attached to the specimen to measure the crack mouth opening displacement. All data of load versus clip gauge displacement are acquired with a sampling rate of $50 \mathrm{~Hz}$. After fracture, the crack length prior to final monotonic loading is measured using an optical microscope following the ASTM E1820-09 standard procedure.

\section{Results and discussion}

\subsection{Microstructure}

The optical micrograph shown in Figure 2a-c illustrates a representative example of the $\mathrm{FC}, \mathrm{SC}$, and $\mathrm{SC}+\mathrm{Sb}$ material microstructure, respectively. It can be noted that the microstructure is highly inhomogeneous, being composed of a predominantly ferritic matrix in which graphite domains of different size are unevenly distributed. In some regions, the matrix is even pearlitic. The effect of the cooling rate on the graphite nodules is evident, as their size is much smaller in the FC than in the $\mathrm{SC}$ and $\mathrm{SC}+\mathrm{Sb}$ conditions. To better characterize type, shape and distribution of the graphite particles, ten cross-sections randomly extracted from the samples are metallographically prepared and statistically analysed. Specifically, the deviation from the spherical shape is estimated by the shape factor expressed as:

$$
f_{0}=\frac{4 \pi A}{U^{2}}
$$

where $A$ and $U$ are the area and perimeter of the particles, respectively. Graphite nodules are identified as spheroidal if their shape factor $f_{0}$ is larger than 0.35 . Table 1 summarizes the results of the statistical analysis of the graphite morphology.

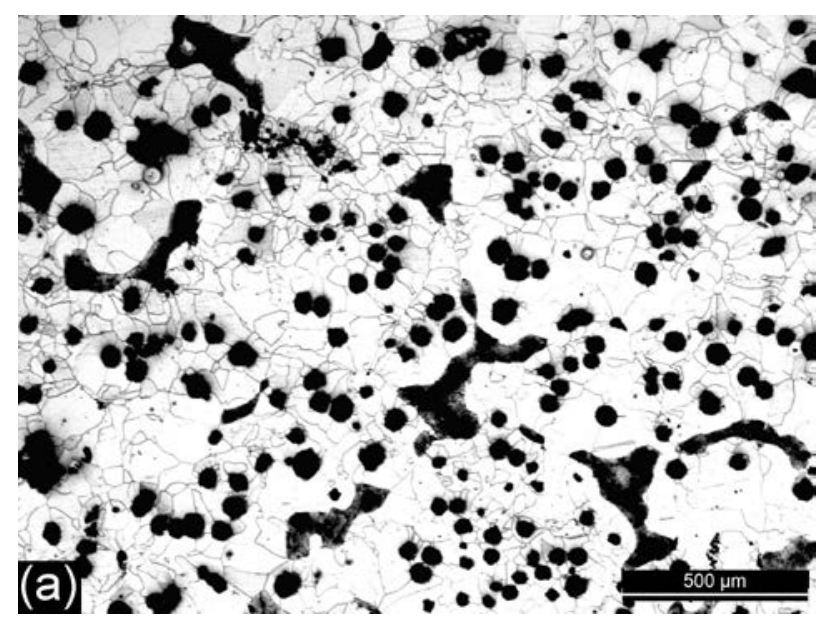

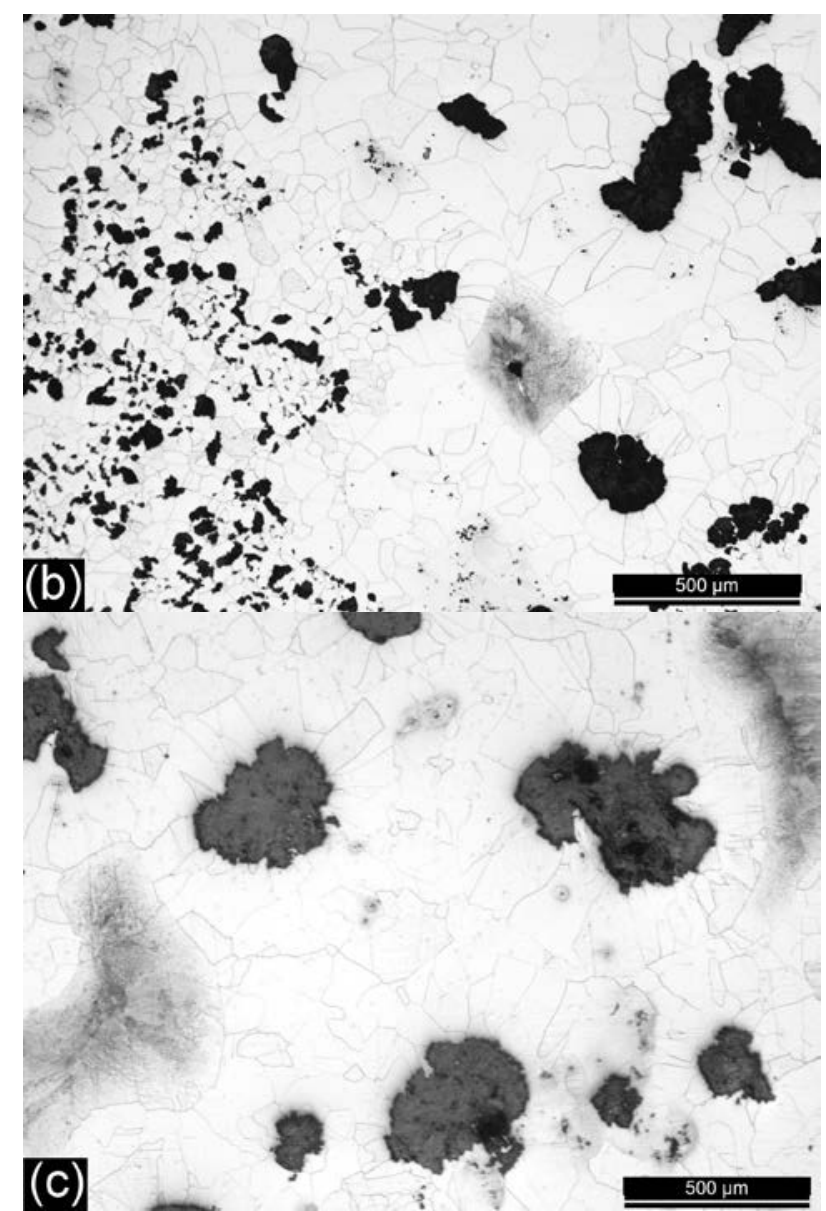

Fig. 2. Optical micrograph of the microstructure (etching with $2 \%$ Nital reagent). (a) FC, (b) SC, and (c) $\mathrm{SC}+\mathrm{Sb}$ condition.

Table 1. Results of quantitative analysis done on 10 metallographic samples. Standard error corresponds to $1 \sigma$ uncertainty band.

\begin{tabular}{|c|c|c|c|c|}
\hline Condition & $\begin{array}{c}\text { Total } \\
\text { Graphite } \\
\text { Content } \\
\mathbf{( \% )}\end{array}$ & $\begin{array}{c}\text { Fraction of } \\
\text { Spheroidal } \\
\text { Graphite } \\
\mathbf{( \% )}\end{array}$ & $\begin{array}{c}\text { Diameter of } \\
\text { Spheroidal } \\
\text { Graphite } \\
(\boldsymbol{\mu})\end{array}$ & $\begin{array}{c}\text { Shape Factor } \\
\text { Spheroidal } \\
\text { Graphite } \mathbf{f}_{\mathbf{0}}\end{array}$ \\
\hline $\mathrm{FC}$ & $9.9 \pm 1.7$ & $79 \pm 7$ & $41 \pm 23$ & $0.67 \pm 0.15$ \\
\hline $\mathrm{SC}$ & $9.3 \pm 2.1$ & $71 \pm 15$ & $310 \pm 110$ & $0.49 \pm 0.19$ \\
\hline $\mathrm{SC}+\mathrm{Sb}$ & $12 \pm 5$ & $72 \pm 18$ & $104 \pm 95$ & $0.63 \pm 0.16$ \\
\hline
\end{tabular}

It can be noted that the fraction of spheroidal graphite increases from 70 to $80 \%$ with increasing cooling rate. The size of the nodules of spheroidal graphite is on the order of 40 micron in the FC cooling and increases in the slow cooled conditions, especially in the absence of inoculants. The remaining fraction of graphite has very different morphology in $\mathrm{SC}$ and $\mathrm{SC}+\mathrm{Sb}$ conditions. In the former, it is mainly in the form of a fine distribution of chunky graphite, while in the latter in the form of large exploded nodules, as shown in Fig. $1 \mathrm{~b}$ and c, respectively. 


\subsection{Monotonic and high-cycle fatigue properties}

Mean values of materials parameters obtained from the analysis of tensile, hardness and fatigue data are summarized in Table 2. For comparison purposes, Table 2 reports also the requirements prescribed by the standard EN-1563 [10] on the tensile properties of samples extracted from bars and guidance values of mechanical properties measured on samples cut from moderately-thick walled castings $(60 \mathrm{~mm}<t \leq 200 \mathrm{~mm})$ of EN-GJS-400-15.

Table 2. Monotonic tensile (based on four replicated tests) and rotating bending fatigue properties. Standard error corresponds to $1 \sigma$ uncertainty band.

\begin{tabular}{|c|c|c|c|c|c|}
\hline Condition & $\begin{array}{c}\sigma_{\mathrm{YS}} \\
(\mathbf{M P a})\end{array}$ & $\begin{array}{c}\sigma_{\mathrm{U}} \\
(\mathbf{M P a})\end{array}$ & $\begin{array}{l}\text { T.E. } \\
(\%)\end{array}$ & HB & $\begin{array}{c}\sigma_{\text {lim,-1 }} \\
(\mathbf{M P a}) \\
\end{array}$ \\
\hline $\mathrm{FC}$ & $290 \pm 2$ & $405 \pm 4$ & $11 \pm 1$ & $152 \pm 3$ & $\begin{array}{c}199 \pm \\
13 \\
\end{array}$ \\
\hline $\mathrm{SC}$ & $275 \pm 4$ & $295 \pm 8$ & $\begin{array}{c}2.9 \pm \\
0.2 \\
\end{array}$ & $144 \pm 2$ & $138 \pm 4$ \\
\hline $\mathrm{SC}+\mathrm{Sb}$ & $290 \pm 2$ & $\begin{array}{c}310 \pm \\
10 \\
\end{array}$ & $\begin{array}{c}1.9 \pm \\
1.1 \\
\end{array}$ & $156 \pm 6$ & $\begin{array}{c}156 \pm \\
10 \\
\end{array}$ \\
\hline $\begin{array}{c}\text { EN-GJS- } \\
400-15 \\
\text { bar [10] }\end{array}$ & 240 & 370 & 11 & $\begin{array}{c}135- \\
180\end{array}$ & - \\
\hline $\begin{array}{c}\text { EN-GJS- } \\
400-15 \\
\text { casting } \\
{[10]}\end{array}$ & 230 & 350 & 8 & - & - \\
\hline $\begin{array}{r}\sigma_{\mathrm{YS}}: \\
\text { elonga }\end{array}$ & $\begin{array}{r}\text { ield str } \\
\mathrm{HB}: \mathrm{Br} \\
\mathrm{st}\end{array}$ & $\begin{array}{l}\text { U: ult } \\
\text { hardn } \\
h \text { at fi }\end{array}$ & on & $\begin{array}{l}\text { gth; T.E } \\
\text { bending }\end{array}$ & $\begin{array}{l}\text { otal } \\
\text { atigue }\end{array}$ \\
\hline
\end{tabular}

As expected, the FC condition displays the highest tensile and fatigue strength. The former are higher than that suggested in [10] for moderately thick-walled castings. Conversely, the very long solidification time and the resulting microstructural alterations lead to low values of tensile strength, total elongation, and fatigue strength; the addition of Sb partially limits the decrement in tensile and fatigue strength. SEM analyses are carried out to shed light on the damage mechanisms acting in the high-cycle fatigue regime.

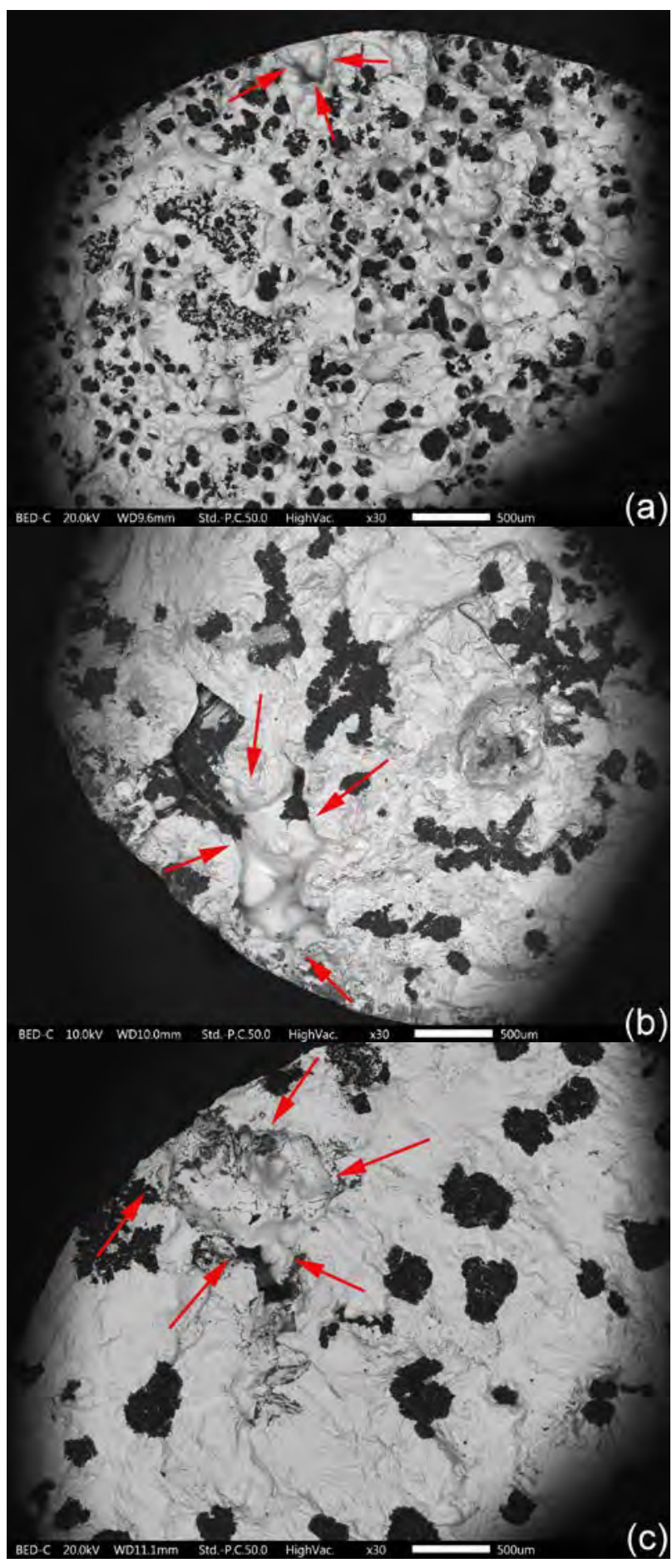

Fig. 3. SEM micrographs of the fracture surfaces of rotating bending fatigue samples around the largest shrinkage pore marked by red arrows: (a) $\mathrm{FC}$, (b) $\mathrm{SC}$, and (c) $\mathrm{SC}+\mathrm{Sb}$ condition. 


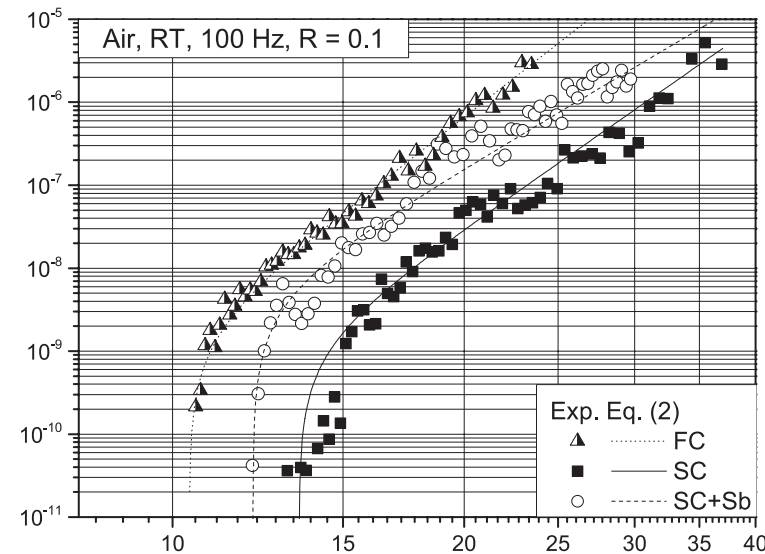

(a)

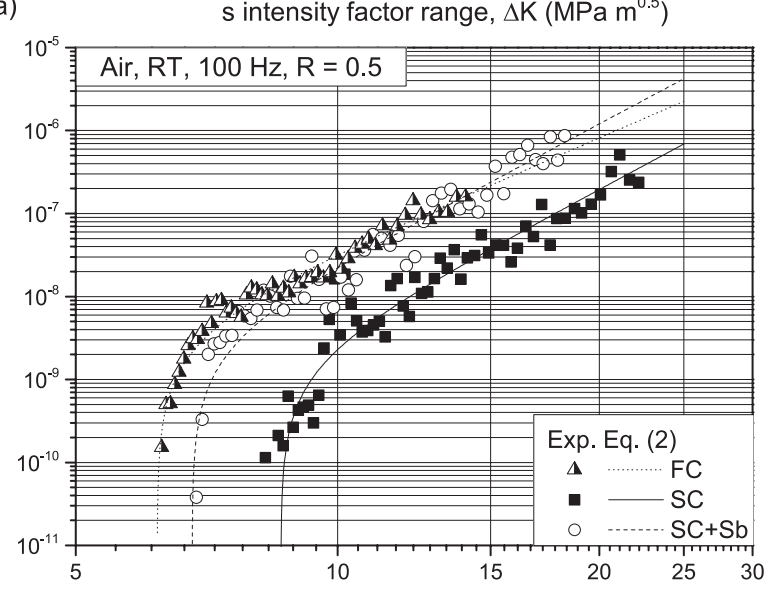

(b)

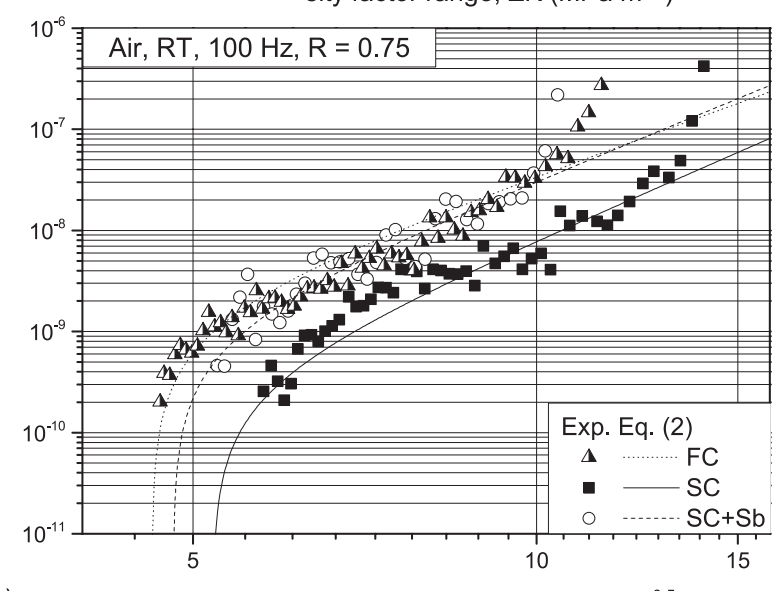

(c)

ge, $\Delta \mathrm{K}\left(\mathrm{MPa} \mathrm{m}{ }^{0.5}\right)$

Fig. 4. Fatigue crack growth curves plotted as a function of the nominal stress intensity factor range. Load ratio (a) $R=0.1$, (b) $R=0.5$, and (c) $R=0.75$.

Figure 3a-c shows the fracture surface of fatigue samples in $\mathrm{FC}, \mathrm{SC}$, and $\mathrm{SC}+\mathrm{SB}$ condition, respectively, tested at stress levels close to the fatigue limit. It can be noted that shrinkage defects (marked by red arrows) are preferential site of crack initiation. Their size is significantly lower in the $\mathrm{FC}$ than in the $\mathrm{SC}$ and $\mathrm{SC}+\mathrm{Sb}$ condition. The graphite nodules are fairly uniformly distributed in the FC condition, while in the SC and $\mathrm{SC}+\mathrm{Sb}$ conditions the crack initiation site is located in regions of low graphite content. According to Murakami and Endo model [11], the fatigue limit of DCI is related to the size of the critical defect and to the hardness of the ferritic matrix. By the light of this model, the highest fatigue limit of the FC condition is essentially due to the smaller defect size. The superior fatigue strength of the $\mathrm{SC}+\mathrm{Sb}$ with respect to the $\mathrm{SC}$ condition is supposed to be related to the absence of chunky graphite.

\subsection{Fatigue crack growth curves}

The resulting $\mathrm{d} a / \mathrm{d} N-\Delta K$ curves obtained at load ratios $R=0.1,0.5$ and 0.75 are compared in Figure $4 \mathrm{a}-\mathrm{c}$, respectively. At all the explored load ratios, the highest fatigue crack growth resistance is exhibited by the SC condition, while the $\mathrm{SC}+\mathrm{Sb}$ material shows an intermediate behaviour. The experimental data are fitted by the exponential law proposed by Klesnil and Lukáš [12]:

$$
\frac{\mathrm{da}}{\mathrm{d} N}=C\left(\Delta K^{m}-\Delta K_{t h}^{m}\right)
$$
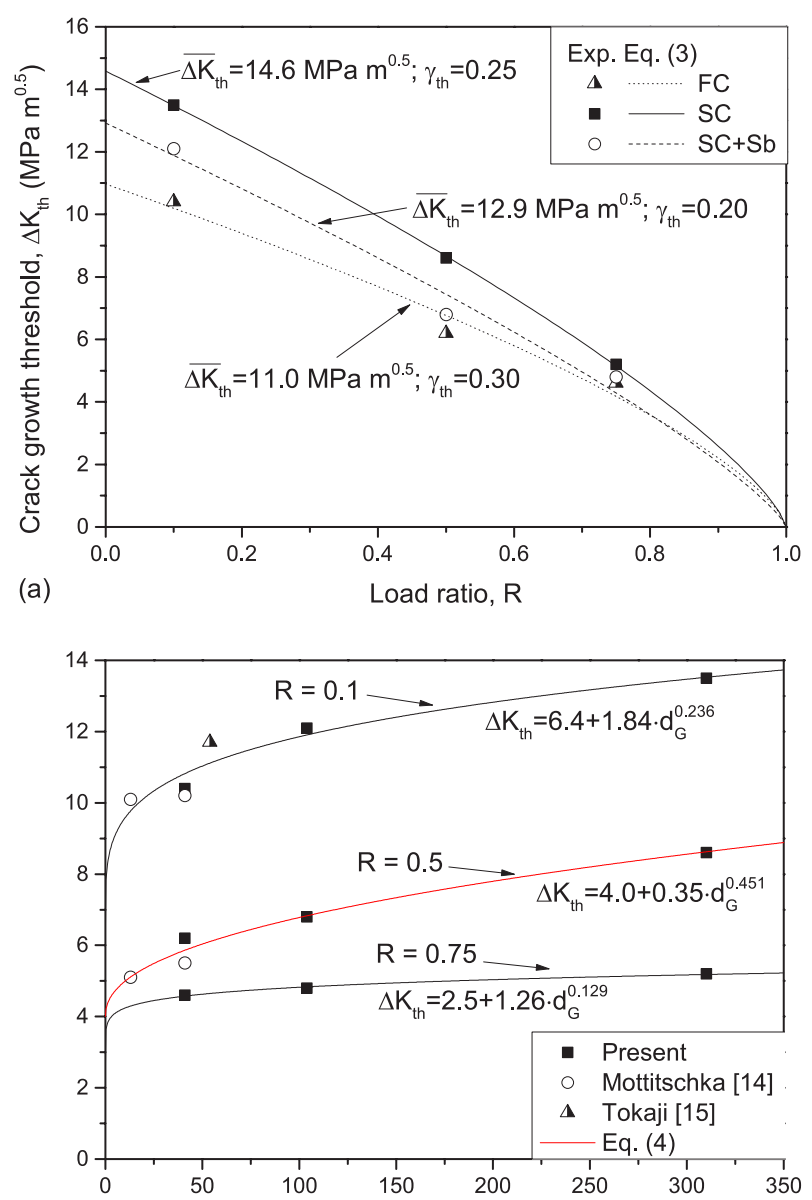

b)

Fig. 5. Threshold dependency upon (a) load ratio $R$ and (b) mean diameter of spheroidal graphite.

The best-fit parameters are given in Table 3 for the different load ratios used in the tests.

The R-dependency of the threshold $\Delta K_{t h}$ is well represented by the Walker equation [13]:

$$
\Delta K_{\text {th }}=\overline{\Delta K}_{\text {th }}(1-R)^{1-\gamma_{\text {th }}}
$$


as shown in Figure 5a, where the least-square fit of Equation (4) is compared for all the material types. Figure $5 \mathrm{~b}$ depicts the threshold $\Delta K_{t h}$ as a function of the mean graphite diameter $\mathrm{d}_{\mathrm{G}}$ and compares the outcomes of the present paper with the results published in the technical literature $[14,15]$ for EN-GJS-400 DCI with similar chemical composition.

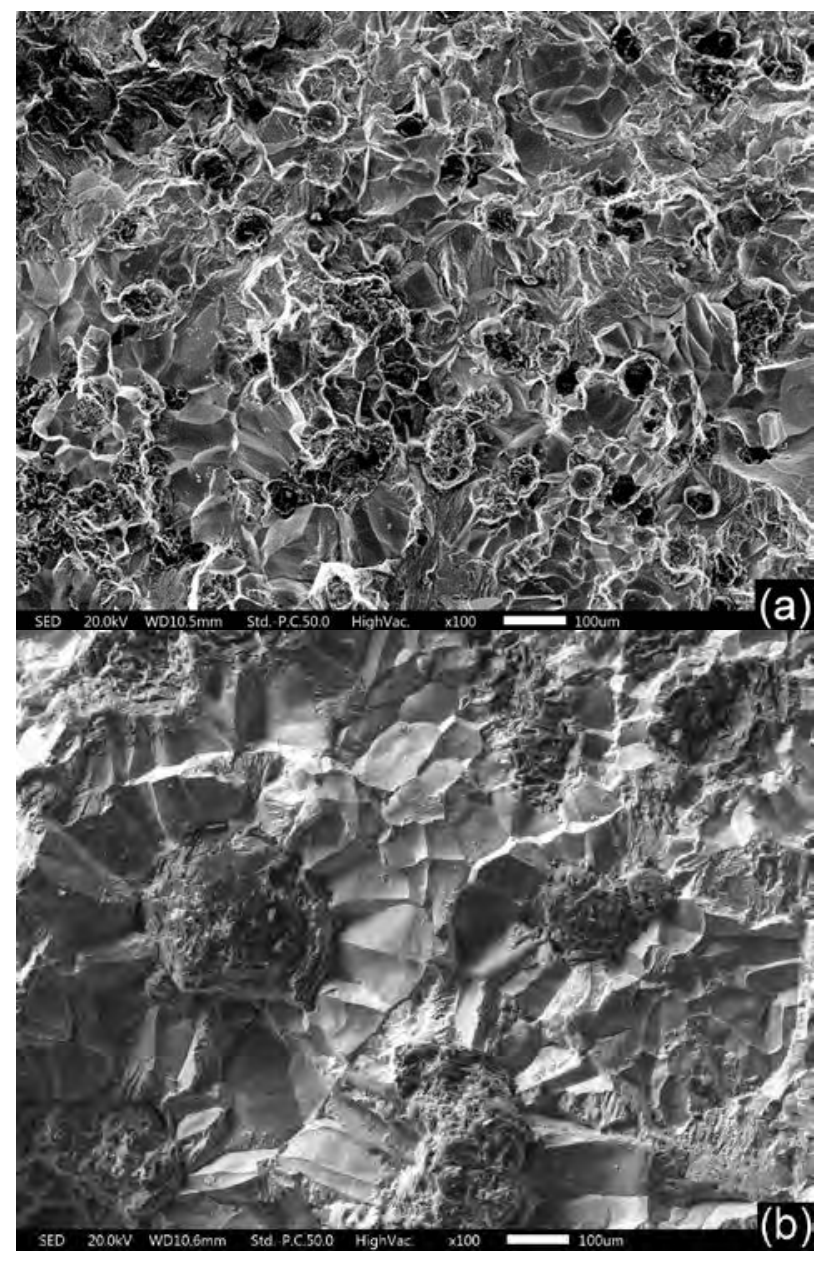

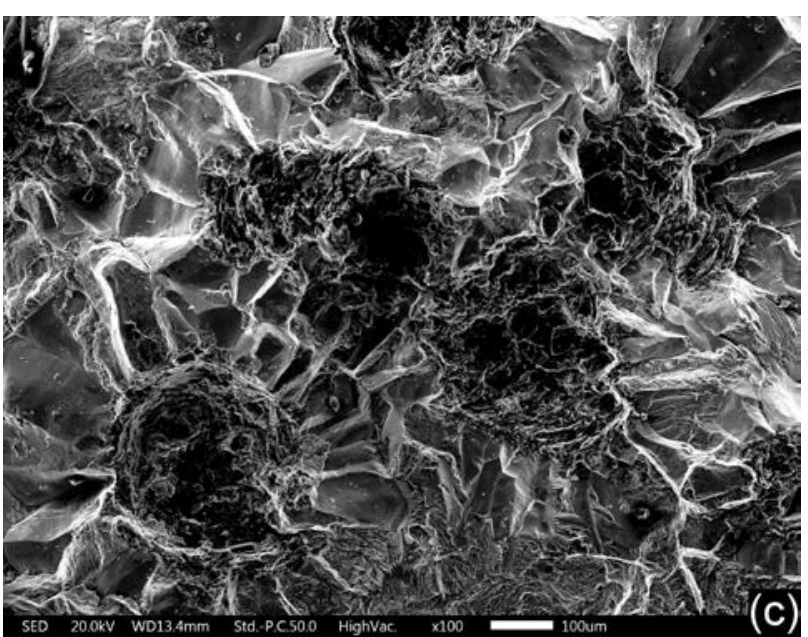

Fig. 6. SEM) micrographs of the fatigue fracture surfaces of the $\mathrm{C}(\mathrm{T})$ sample tested at $\mathrm{R}=0.1$ : (a) $\mathrm{FC}$, (b) $\mathrm{SC}$, and (c) $\mathrm{SC}+\mathrm{Sb}$ condition.

Table 3. Best-fit parameters of the crack propagation law expressed by Equation (2).

\begin{tabular}{|c|c|c|c|c|}
\hline Condition & Load ratio $R$ & $\Delta K_{\text {th }}\left(\mathrm{MPa} \cdot \mathrm{m}^{0.5}\right)$ & $C$ & $m$ \\
\hline \multirow{3}{*}{$\mathrm{FC}$} & 0.1 & 10.4 & $8.33 \times 10^{-19}$ & 9.1 \\
\hline & 0.5 & 6.2 & $1.03 \times 10^{-12}$ & 4.5 \\
\hline & 0.75 & 4.6 & $3.13 \times 10^{-12}$ & 4.1 \\
\hline \multirow{3}{*}{$\mathrm{SC}$} & 0.1 & 13.5 & $7.72 \times 10^{-19}$ & 8.1 \\
\hline & 0.5 & 8.6 & $9.48 \times 10^{-15}$ & 5.6 \\
\hline & 0.75 & 5.2 & $9.59 \times 10^{-14}$ & 4.9 \\
\hline \multirow{3}{*}{$\mathrm{SC}+\mathrm{Sb}$} & 0.1 & 12.1 & $1.56 \times 10^{-16}$ & 6.9 \\
\hline & 0.5 & 6.8 & $6.32 \times 10^{-14}$ & 5.6 \\
\hline & 0.75 & 4.8 & $7.49 \times 10^{-13}$ & 4.6 \\
\hline
\end{tabular}




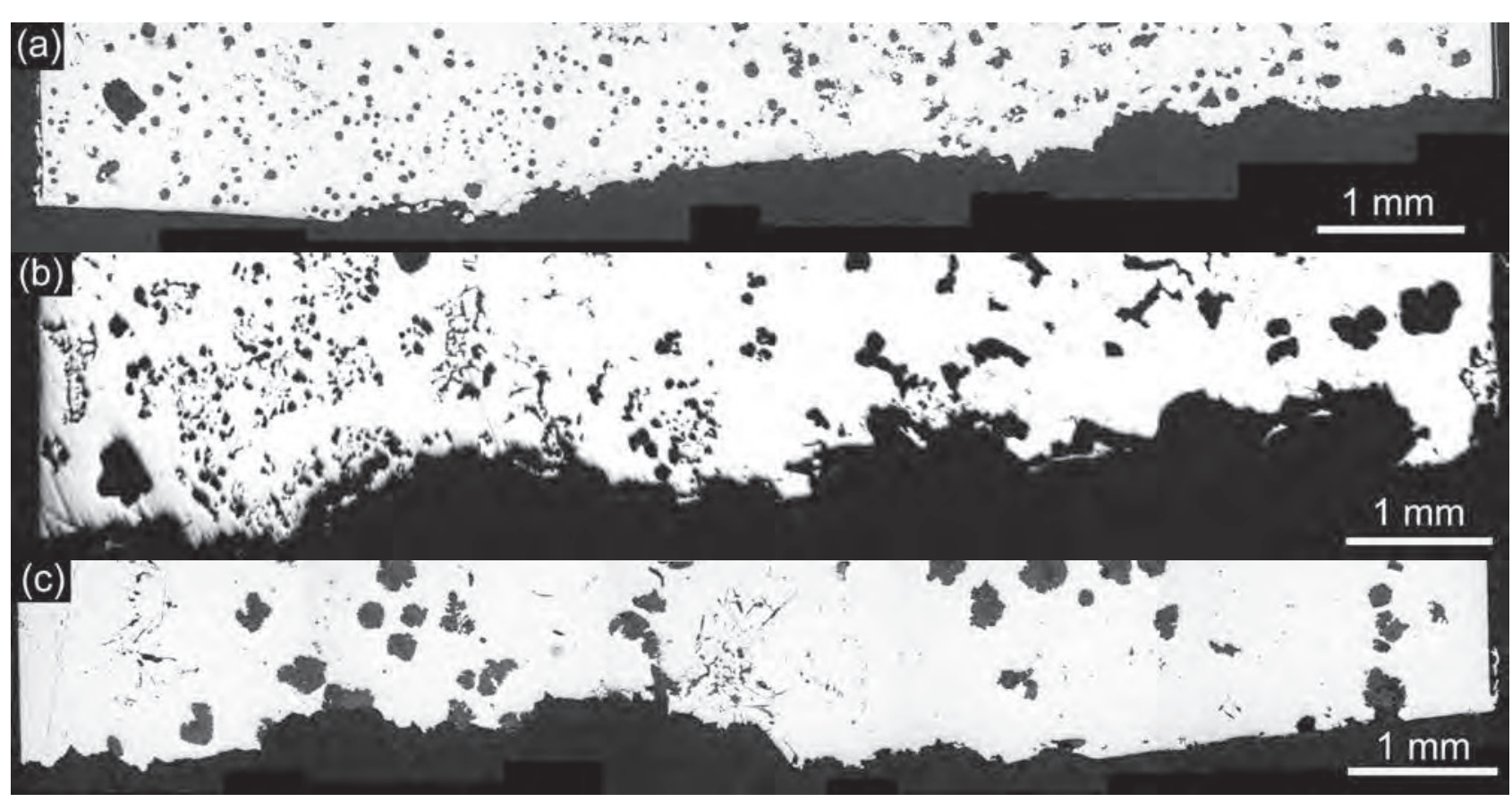

Fig. 7. Light microscope images of crack front profiles taken in the near-threshold crack propagation region of the $\mathrm{C}(\mathrm{T})$ samples tested at $\mathrm{R}=0.1$ : (a) $\mathrm{FC}$, (b) SC, and (c) $\mathrm{SC}+\mathrm{Sb}$ condition.

Figure $5 \mathrm{~b}$ shows that there exists a clear tendency of $\Delta K_{t h}$ to increase with increasing $d_{G}$. As shown in Fig. 5b, this trend is well represented by the following power equation:

$$
\Lambda K_{\text {th }}=\Delta K_{\text {th }}^{0}+a \cdot d_{G}^{b}
$$

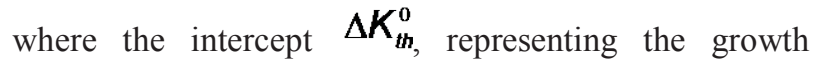
threshold in the absence of graphite, is expressed by the lower bound of $\Delta K_{\text {th }}$ proposed in [16] for various steels:

$$
\Delta K_{\text {th }}^{0}=7.0(1-0.85 R) \quad M P a \sqrt{m}(5)
$$

It can be noted that the effect of the graphite nodule size on the growth threshold is more pronounced at $R=0.1$, while it becomes almost negligible at $R=0.75$.

Figure 6a-c illustrates SEM overviews of the fatigue facture surface in the vicinity of the near-threshold propagation region for the $\mathrm{FC}, \mathrm{SC}$, and $\mathrm{SC}+\mathrm{Sb}$ condition, respectively. All the fracture surfaces are characterized by the presence of different graphite morphologies, ranging from nearly spherical nodules to fine dispersion of chunky graphite. Clearly, the size of the nodules is much smaller in the fast than in the slow cooled conditions. It is worth noticing that the regions containing no graphite at all or surrounding graphite spheroids show large evidence of brittle cleavage and intergranular fracture. On the contrary, the presence of chunky graphite is associated to a less brittle fracture mode resulting in rougher fracture surface.

Similar indications are given by crack front profiles taken from regions under the same crack propagation regime and shown in Fig. 7a-c for the FC, SC, and $\mathrm{SC}+\mathrm{Sb}$ condition, respectively. Indeed, it can be noticed that where the crack front encounters regions characterized by degenerated graphite and large graphite nodules the crack profile is significantly rougher than where only small spherical graphite nodules are present or where graphite is even absent. The former scenario, typical of the slow cooled conditions, especially of the SC material, will result in more effective crack retardation mechanisms, such as roughness-induced crack closure and crack front geometry effects [17], with respect to the latter one prevailingly occurring in the $\mathrm{FC}$ condition.

\subsection{Fracture toughness}

$K_{\text {Ic }}$ fracture toughness tests are performed on $\mathrm{C}(\mathrm{T})$ specimens depicted in Figure 1, whose geometry is taken as large as possible with the aim of satisfying the linear elastic fracture mechanics requirement expressed by [18]:

$$
B, a, W-a>2.5\left(\frac{K_{I c}}{\sigma_{Y S}}\right)^{2}
$$

where $a, B$ and $W$ are the initial crack length, specimen thickness and width, respectively. Considering the value of the material yield strength $\sigma_{Y S}$ listed in Table 2, the maximum theoretical fracture toughness that can be estimated using this $\mathrm{C}(\mathrm{T})$ sample geometry is about 32 MPa m.5.

Table 4. Results of the fracture toughness tests and comparison with literature data.

\begin{tabular}{|c|c|c|c|}
\hline Condition & Specimen & $\begin{array}{c}K_{Q} \\
\left(\mathrm{MPa} \cdot \mathrm{m}^{0.5}\right)\end{array}$ & $\begin{array}{c}K_{\max } \\
\left(\mathrm{MPa} \cdot \mathrm{m}^{0.5}\right)\end{array}$ \\
\hline
\end{tabular}




\begin{tabular}{|c|c|c|c|}
\hline \multirow{2}{*}{ FC } & 1 & 23.5 & 50.9 \\
\cline { 2 - 4 } & 2 & 23.1 & 52.5 \\
\hline \multirow{2}{*}{$\mathrm{SC}$} & 1 & 18.0 & 57.3 \\
\cline { 2 - 4 } & 2 & 16.6 & 50.2 \\
\hline \multirow{2}{*}{$\mathrm{SC}+\mathrm{Sb}$} & 1 & 27.9 & 51.3 \\
\cline { 2 - 4 } & 2 & 26.5 & 44.8 \\
\hline \multirow{2}{*}{ Ref. [19] } & $\mathrm{C}(\mathrm{T})$ & 20 & 39 \\
\hline
\end{tabular}

Table 4 summarizes the results of the two fracture toughness tests and compares them with data found in [19] regarding similar EN-GJS-400 DCI subjected to normal solidification conditions. $K_{Q}$ is the apparent fracture toughness determined from load $P_{Q}$, viz. the intersection of the force versus crack opening displacement record with the $95 \%$ secant. $K_{\max }$ is obtained from the maximum value of the load record. In order for $K_{Q}$ to be qualified as linear elastic, plane-strain fracture toughness, the ratio $K_{\max } / K_{Q}$ must be $\leq 1.10$. It can be noted that, despite the use of thick-walled and side-grooved specimens, no test listed in Table 3 met this requirement, thus resulting in thickness-dependent fracture toughness values. The FC condition displays an apparent fracture toughness slightly higher than that reported in [19] for a similar material, even though a much thicker specimen was used $(32 \mathrm{~mm}$ vs. $10 \mathrm{~mm}$ thickness). The effect of slow cooling conditions is not evident, in the sense that the marked overgrowth of the nodules occurred in SC seems to be slightly detrimental effect on the fracture toughness. On the contrary, the addition of inoculants, which limits the graphite degeneration, seems to have a beneficial effect, resulting in a small increment in fracture toughness.

\section{Conclusions}

In this paper, the effect of $\mathrm{Sb}$ and solidification time on the mechanical properties of an EN-GJS-400-type ferritic ductile cast iron (DCI) was explored. The following conclusions can be drawn:

1) The microstructure consists of a prevailing ferritic matrix, in which $3 / 4$ of graphite is interspersed in form of spheroidal nodules. Their size is smaller in the fast cooled condition and largest in the slow cooled condition without the addition of $\mathrm{Sb}$. The rest of graphite is present in the form of chunky (SC) or exploded $(\mathrm{SC}+\mathrm{Sb})$ graphite.

2) The slow cooled conditions exhibit a tensile strength and a total elongation $20 \%$ and $75 \%$ lower than the fast cooled material.

3) The fatigue limit of the slow cooled condition is about 30\% lower than that of the fast cooled material. The addition of $\mathrm{Sb}$ limits this decrement down to $20 \%$. The fatigue limit is strongly correlated to the dimension of the largest shrinkage pore found on the fracture surface.

4) The slow cooled conditions, especially that without the addition of $\mathrm{Sb}$, display a significantly higher fatigue crack growth resistance, especially in the near-threshold regime and at low load ratio, with respect to DCI subject to fast solidification conditions. The fatigue crack growth threshold seems to be correlated to the mean size of the graphite nodules. Their presence in conjunction with chunky graphite makes the crack front profile much rougher, resulting in more effective crack retardation mechanisms. Further investigations are needed to reveal a possible correlation of the crack threshold with the size of the chunky graphite domains.

5) The effect of slow cooling condition on the fracture toughness is not evident, in the sense that the marked overgrowth of the nodules occurred in SC seems to be slightly detrimental effect on the fracture toughness. On the contrary, the addition of inoculants, which limits the graphite degeneration, seems to have a beneficial effect, resulting in a small increment in fracture toughness.

\section{References}

1. H. Kaufmann, D.B. Wolters, Giess 27, 4-27 (2002).

2. P. Minnebo, K.F. Nilsson, D. Blagoeva, J. Mater. Eng. Perform. 16, 35-45 (2007).

3. M. Kobayashi, J. Yamabe, Fatigue Fract. Eng. Mater. Struct. 29, 403-415 (2006).

4. H. Kaufmann, D.B. Wolters, Konstr. Giess. 27, 427 (2002).

5. I. Riposan, M. Chisamera, V. Uta, S. Stan, Int. J. Metalcast. 8, 65-80 (2014)

6. M.I. Onsøien, Ø. Grong, T. Skaland, K. Jørgensen, Mater. Sci. Technol. 15, 253-259 (1999).

7. J.O. Choi, J.Y. Kim, C.O. Choi, J.K. Kim, P.K. Rohatgi, Mater. Sci. Eng. A 383, 323-333 (2004).

8. E. Foglio, M. Gelfi, A. Pola, S. Goffelli, D. Lusuardi, Int. J. Metalcast. 11, 33-43 (2017).

9. M. Benedetti, E. Torresani, V. Fontanari, D. Lusuardi, Metals 7, 88 (2017).

10. European Standard EN 1563:2011. FoundingSpheroidal Graphite Cast Iron; CEN: Brussels, Belgium, 2011.

11. Murakami, Y.; Endo, M. In The Behaviour of Short Fatigue Cracks (Institution of Mechanical Engineers: London, UK, 1986).

12. M. Klesnil, P. Lukáš, Eng. Fract. Mech. 4, 77-92 (1972).

13. E.K. Walker, In Effect of Environment and Complex Load History on Fatigue Life (American Society for Testing and Materials, West Conshohocken, PA, USA, 1970). 
14. T. Mottitschka, G. Pusch, H. Biermann, L. Zybell, M. Kuna, Procedia Eng. 2, 1557-1567 (2010).

15. K. Tokaji, T. Ogawa, K. Shamoto, Int. J. Fatigue 16, 344-350 (1994).

16. N. E. Dowling, Mechanical Behavior of Materials (International Edition Pearson, 2007).

17. M. Benedetti, J. Heidemann, J.O. Peters, G. Lütjering, Fatigue Fract. Eng. Mater. Struct. 28, 909-922 (2005).

18. T.L Anderson, Fracture Mechanics: Fundamentals and Applications (CRC Press, Boca Raton, FL, USA, 2005).

19. H.R. Zambrano, G. Härkegård, K.F. Stärk, Fatigue Fract. Eng. Mater. Struct. 35, 374-388 (2011). 